\title{
Patent-Based Technology Life Cycle Analysis: The Case of the Petroleum Industry
}

\author{
Mohammad Dehghani Madvar ${ }^{a}$ \\ Researcher and Expert, dehghani.madvar@gmail.com \\ Hossein Khosropour ${ }^{\mathrm{b}}$ (corresponding author) \\ Consultant and Expert, khosropourh@gmail.com \\ Abdollah Khosravanian ${ }^{c}$ \\ Researcher and Expert, khosravanian_a@che.sharif.ir \\ Maryam Mirafshar ${ }^{\text {d }}$ \\ Graduate Student, mirafshar.maryam@gmail.com
}

Adel Azaribeni ${ }^{c}$

Researcher and Expert, Azaribeni_adel@che.sharif.ir

Morteza Rezapour ${ }^{\mathrm{e}}$

Head of IP Unit, rezapourm@ripi.ir

Behrouz Nouri ${ }^{\mathrm{e}}$

Head of Technology Strategies Unit, Noorib@ripi.ir

\footnotetext{
a Department of Renewable Energy, University of Tehran, 16 Azar str., Enghelab sq., Tehrān, Iran.

b Young Researchers and Elite Club, Central Tehran Branch Islamic Azad University, No. 136, Forsat Sr., Eskandari St., Azadi Ave., Tehran, Tehran Iran

${ }^{c}$ Department of Chemical and Petroleum Engineering, Sharif University of Technology, Azadi ave., Tehrān, Iran

d Allameh Tabatabai University, Dehkadeh-ye-Olympic, Tehrān, Iran.

e Research Institute of Petroleum Industry, West Side of Azadi Sports Complex, 1485733111 Tehrān, Iran.
}

\begin{abstract}
$\mathrm{D}$ ecisions for determining the current stage of technology life cycle (TLC) based on reliable data, are necessary. The inherent links between patents and science and technology make them essential sources for data on any technology. In the light of this, and considering the importance of patent information for the firm's strategic decisions, we have attempted to use patent data as a source of information to identify the level of a technology in the S-Curve. This paper starts with the literature review of the life cycle and the role of patents at
\end{abstract}

Abstract

Keywords: technology life cycle; S-curve; patent analysis; $\mathrm{CO}_{2}$ injection.

DOI: 10.17323/1995-459X.2016.4.72.79. the various stages of technology development, and then focuses on a technology trend analysis framework using patent data, and discusses the life cycle of $\mathrm{CO}_{2}$ injection technology in the upstream sector of the global oil and gas industry. In the final section, the results are presented based on an analysis of patent data on $\mathrm{CO}_{2}$ injection technology as were recommendations concerning the application of the methodology in future studies as it might be an effective tool for better analyzing any desired technology.

Citation: Madvar M.D., Khosropour H., Mirafshar M., Khosravanian A., Azaribeni A., Rezapour M., Nouri B. (2016) Patent-Based Technology Life Cycle Analysis: The Case of the Petroleum Industry. Foresight and STI Governance, vol. 10 , no 4 , pp. $72-79$. DOI: $10.17323 / 1995-$ 459X.2016.4.72.79. 
$\mathrm{P}$ atents provide one of the most important ways to the improve the competitive strategy of an enterprise's business concept and its technology strategy. The monitoring of patenting activities helps identify the status of a technology in its life cycle; and determine competitive or collaborative relations among companies in certain areas, which can provide valuable information for developing strategies for R\&D and marketing activities [Dou, 2004]. Patent analysis provides a practical forecasting tool for decision makers in the public and private sectors [Amy, Charles, 2008]. Patent analysis can provide a picture of the growth pattern of a technology (as emerging, maturing or declining). Due to the tendency for tracing technological changes and their influence on industries, there is an increasing demand for the use of Technology Forecasting (TF) methods to improve policy planning and implementation. TF predicts the direction and speed of change in technological trends, facilitating the early detection of revolutionary technologies [Chen et al., 2011]. Such an early detection of weak signals helps researchers prepare for the turbulent future of an industry as well as technology and TF is therefore an unavoidable process for devising successful policies which can meet both public and private needs.

The oil and gas industry is one of the key sectors in the economy and the fact that technological changes have become an indisputable fact in this industry motivated us to choose a segment of this sector for technological forecasting using life cycle tools [Daim et al., 2006].

Among the technologies used in the upstream sector of the oil and gas industry, Enhanced Oil Recovery (EOR), also known as tertiary production, is a prominent area. $\mathrm{CO}_{2}$ injection (Figure 1), more specifically speaking, is quickly becoming the preferred method of EOR in many fields, due to the ease of $\mathrm{CO}_{2}$ transport through pipelines (from areas where it is abundant to the fields where it is needed). In addition, there is the overall advantage of recycling this greenhouse gas by injecting it into reservoirs for EOR [Malik, Islam, 2000].

\section{The concept of technological life cycles}

The S-Curve is a mathematically based model which is used in a variety of fields including physics, biology and economics. According to Arthur Little's definition, the characteristic of the emerging stage is a new technology with low competitive impact and low integration in products or processes [Little, 1981]. During the growth stage, there are pacing technologies with high competitive impacts that have not yet been integrated in new products or processes. At the maturity stage, some pacing technologies turn into key technologies, they are integrated into products or processes, and maintain their high competitive impact [Mogee, 1991]. As soon as a technology loses its competitive impact, it becomes a base technology and enters the saturation stage and may be replaced by a new technology (Figure 2).

As made clear in Figure 2, the most critical issues under consideration are the 'Technological Limitation' and 'Productivity Ratio Change.' Productivity Ratio Change is defined as a turning point developed by any new capability. This development is is produced at an established company. The other term is defined as a

\section{Figure 1. $\mathrm{CO}_{2}$ Injection}

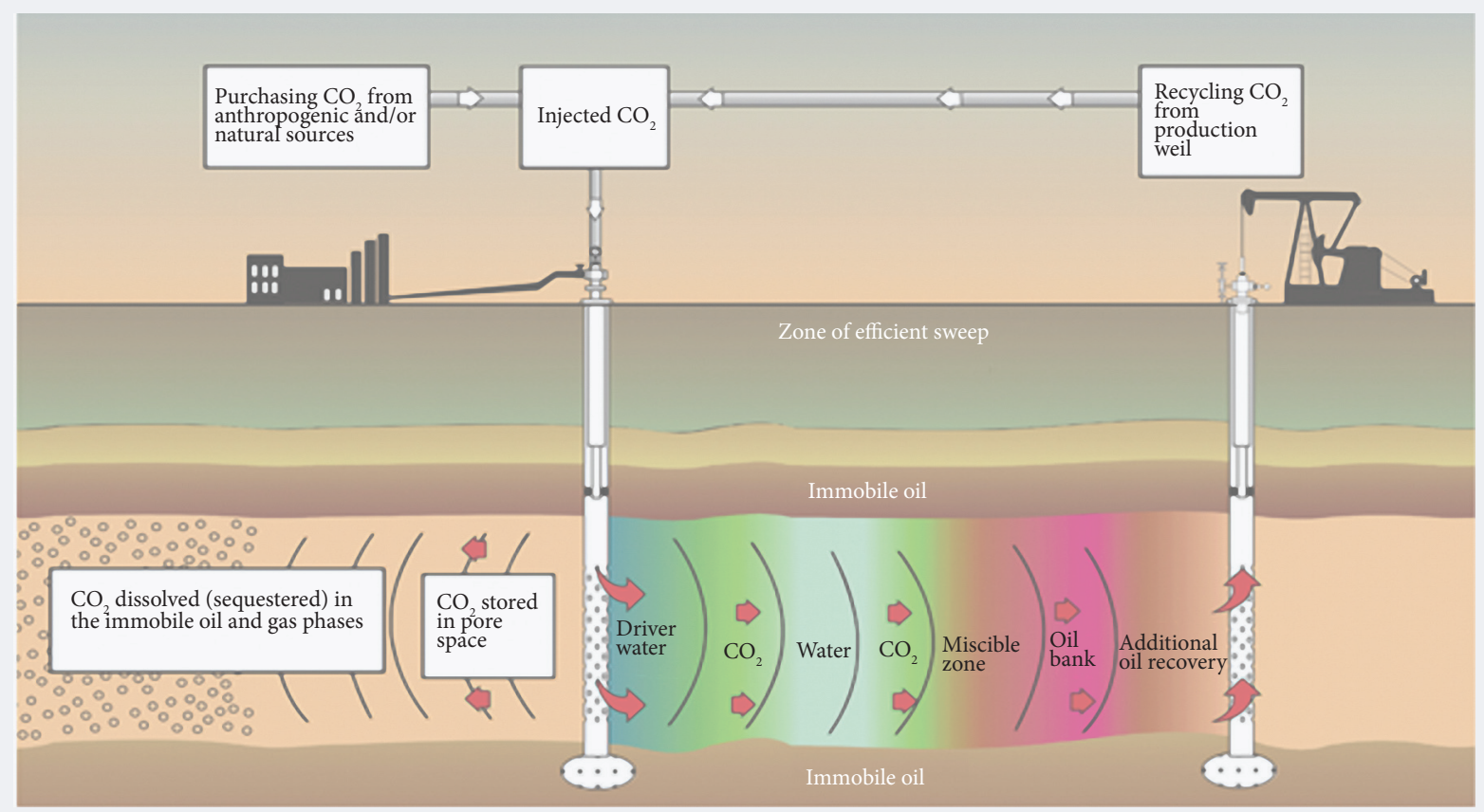

Source: [DOE, 2011]. 


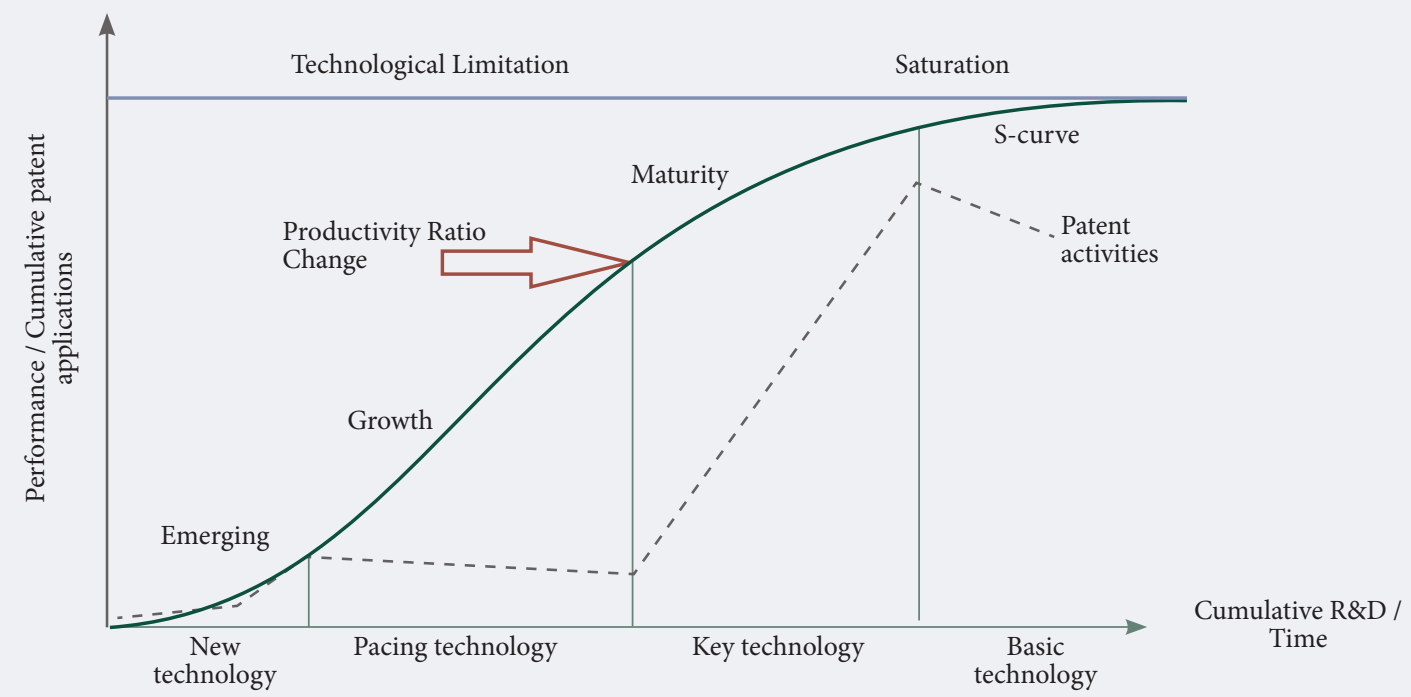

Source: [Ernst, 2003].

technology, which due to finite improvement, becomes mature, thus it is called Technological Limitation. Process innovation often occurs at this level.

S-Curves are acquired by using a regression model that examines the non-linearity between the dependent variable (to be forecasted) and time. The most commonly used equation was described by Intepe and Koc [Intepe, Koc, 2012] as:

$Y_{t}=\frac{L}{1+a e^{-b t}}$,

Where coefficients $a$ and $b$ describe, the location and shape of the curve respectively, and $L$ is the asymptotic maximum value of $Y_{t}$. Models based on initial data for a growth curve are quite valid if the exact curve and upper limit have been identified.

\section{Technological forecasting by patent documents}

Since patents provide exclusive rights and legal protection for assignees and inventors, they play an important role in the development of technology. On the other hand, considering the fact that the patenting process is costly and can take several years, filing a patent generally means there is optimism concerning the economic or technical contribution of the technology being patented.

Patent analysis is used for deriving information about a particular industry or technology, which can be used in forecasting activities. The rate of growth of the number of patents on a technology generally follows a similar trend resembling the S-curve pattern. In the early stages of a technology, the number of patents issued is very limited, next a period of rapid growth follows when the number of field and issued patents increases and finally a plateau is reached [Amy, Charles, 2008].

Using the number of patent applications, grants, as well as the abandoned, nullified or expired patents can help on obtain insight into the development of a technology. Each technological development goes through three stages starting with intellectual activity and finally getting to the market. The first transition stage starts with the dawn of the primary idea and continues with basic research, which can be filed as a patent. In the next step the filed patent will be published based on the $R \& D$, which is final step before commercializing and then proceeding to the market (Figure 3).

As shown in Figure 2, in most models, patenting is attributed to the invention and development phase and is considered an output indicator of R\&D activities, and as the models show, there is always a positive relationship between the extent of $\mathrm{R} \& \mathrm{D}$ and the number of patents. The number of citations that a patent gets can also be correlated with its economic and technological value. Since the cited patents, unlike in the case of articles, are preferred to be kept as low as possible by the applicant, in order to avoid possible overlapping arguments by the examination bodies, the number of citations made in a patent is also a very important indicator.

Patent citations can be used for studying the relationships between a company's activity and the other companies that cite the patents. It should be noted that an even smaller share of creativity can turn 


\section{Figure 3. Technological development steps} vs. patent

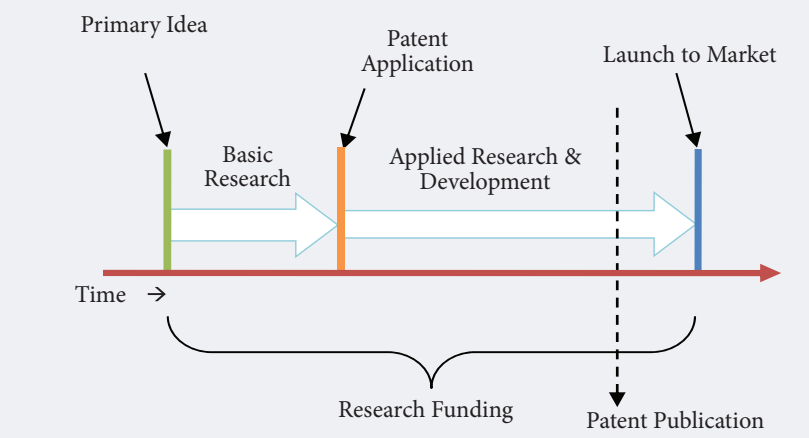

Source: compiled by the authors.

\section{Figure 4. The relationship between patenting, invention and innovation}

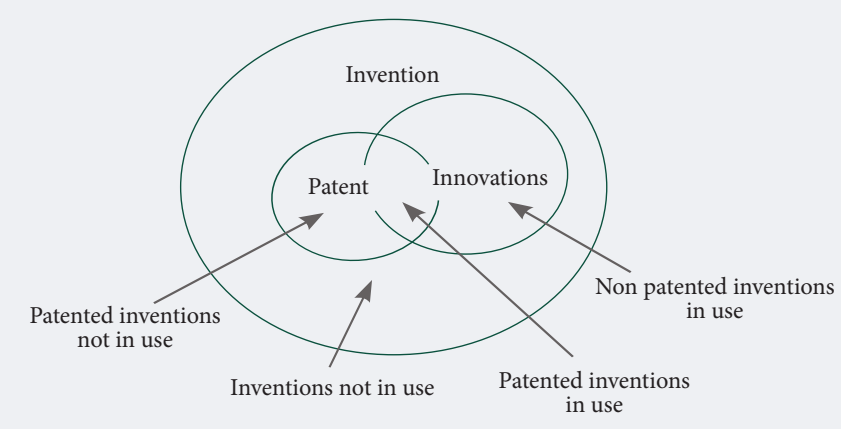

Source: [Basberg, 1987].

into an innovation and in the future some innovations may become inventions and then only some of those inventions will be patented. Patents obviously contain some innovations; a patent may also contain inventions without any commercial value.

\section{Methodology of the study}

The technological life cycle curve is a parametric estimation-based tool for forecasting the future of technology by using growth curves. This method is helpful for estimating and anticipating the level of technological growth at each stage in the life cycle [Gao et al., 2013].

In this paper, in order to illustrate the life cycle of technology used during carbon dioxide injection for enhanced oil recovery, the information of patents has been used. To identify relevant patents at first, we tried to interview experts in order to extract key words related to technology and its use in enhanced oil recovery. At the end of this stage, a list of key words was identified. Based on the list, in the next step by using key codes (extracting International Patent Classification (IPC) ${ }^{1}$ and Cooperative Patent Classification $(\mathrm{CPC})^{2}$ codes using patents) or through the relationship between the identified codes, the main and related codes were extracted.

Finding the relationship between the key codes (Family codes) was the next step that led to the analysis stage. In this step using Orbit software ${ }^{3}$ the relationship between the codes and their transposition is analyzed and identified (Figure 5).

As can be seen in Figure 6, the most patents related to the carbon dioxide injection technologies are E21B43 and C09K8 codes and fewest patent codes are F23L2900, E21B49 and C10J2300. Table 1 gives an idea of the hierarchical structure of $\mathrm{CO}_{2}$ injection technology.

Table 1. International Patent Classification (IPC) of $\mathrm{CO}_{2}$ injection technology

\begin{tabular}{|l|l|}
\hline Code & Definition \\
\hline E & Fixed construction \\
\hline E21 & Earth drilling; mining \\
\hline E21B & $\begin{array}{l}\text { Earth drilling, e.g. deep drilling (mining, quarrying E21C; making shafts, driving galleries or tunnels E21D); obtaining } \\
\text { oil, gas, water, soluble or meltable materials or a slurry of minerals from wells }\end{array}$ \\
\hline E21B43 & $\begin{array}{l}\text { Methods or apparatus for obtaining oil, gas, water, soluble or meltable materials or a slurry of minerals from wells } \\
\text { (applicable only to water E03B; obtaining oil-bearing deposits or soluble or meltable materials by mining techniques } \\
\text { E21C41/00; pumps F04) }\end{array}$ \\
\hline E21B43/16 & $\begin{array}{l}\text { Enhanced recovery methods for obtaining hydrocarbons (fracturing E21B43/26; obtaining slurry E21B43/29; } \\
\text { reclamation of contaminated soil in situ B09C; }\{\text { chemical compositions therefor C09K8/58\}) }\end{array}$ \\
\hline E21B43/164 & $\left\{\right.$ Injecting $\mathrm{CO}_{2}$ or carbonated water (in combination with organic material C09K8/594)\} \\
\hline Source: compiled by the authors using International Patent Classification (IPC). \\
\hline
\end{tabular}

Available at: http://web2.wipo.int/classifications/ipc/ipcpub/\#refresh=page, last accessed 17.02.2016.

Established in 2012 by European Patent Office (EPO) in cooperation with U.S. Patent and Trademark Office (USPTO). Available at: http://www. cooperativepatentclassification.org/, last accessed 17.02.2016.

The Orbit is a Questel patent search and analysis software which is web-based patent with unique features. The patent authority coverage is almost all of the countries that have contributed in high technology and also these countries are pioneers in the technology such as the United States, the Great Britain, Korea and so on. Available at: www.orbit.com, last accessed 24.03.2016. 


\section{Figure 5. Transposition of codes}

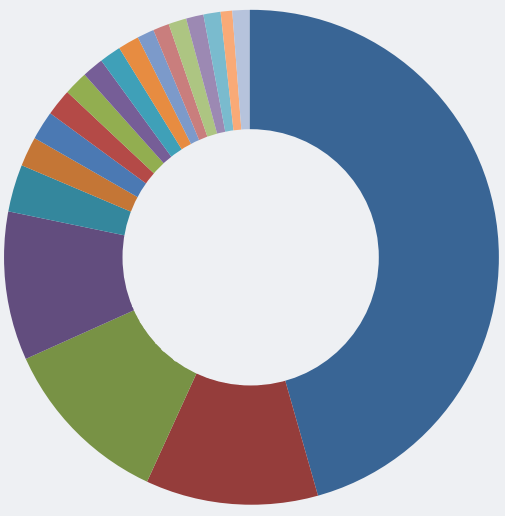

E21B43\00 (1294 patents) - Methods or apparatus for obtaining oil

Y02C10100 (338 patents) $-\mathrm{CO}_{2}$ capture or storage

- C09K8100 (338 patents) - Compositions for drilling of boreholes or wells

- E21B41100 (295 patents) - Equipment or details not covered by groups E21B15 $\backslash 00$ to E21B $40 \backslash 00$

B B1DD 100 (85 patents) - Separation of gases or vapours

- Y10S507\00 (60 patents) - Earth boring

C01B3\00 (56 patents) - Hydrogen

- C10L3\00 (53 patents) - Gaseous fuels

C01B2203100 (46 patents) - Integrated processes for the production of hydrogen or synthesis gas

- Y02E20100 (43 patents) - Combustion technologies with mitigation potential

F2513\00 (40 patents) - Processes or apparatus for separating the constituents of gaseous

B01D2257\00 (39 patents) - Components to be removed

E21B33100 (35 patents) - Sealing or packing boreholes or wells

Y02E60100 (35 patents) - Enabling technologies or technologies with a potential or indirect contribution to GHG emissions mitigation

C01B31100 (34 patents) - Carbon

F23L7\00 (31 patents) - Supplying non-combustible liquids or gases

F23L2900100 (30 patents) - Special arrangements for supplying or treating air or oxidant for combustion

E21B49\00 (30 patents) - Testing the nature of borehole walls

C10J2300\00 (30 patents) - Details of gasification processes

Source: compiled by the authors using IPC and CPC data.

As shown above, the E21B43 code is one of the most applicable codes for carbon dioxide injection, which consists of five subgroups and the largest number of patents are in the E21B43/16 subgroup. Companies such as Shell, IFP, ExxonMobil and Schlumberger have filed patents under these codes and the lowest number of patents filed were under the E21B43/26 code, filers include Baker Hughes Inc. and Halliburton.

Next, the most relevant patents for $\mathrm{CO}_{2}$ injection were extracted and the S-Curve was obtained based on this data. Finally, the research framework is given as follows:

The source of the patent data was the Questel online database ${ }^{4}$. All 1235 patents were collected in the period from 1937 to 2014.

\section{Discussion}

A patent application is submitted to the patent office until the exclusive right of a patent is granted to the inventors. The patent application includes a description of the invention and provides information about its orgin. Patent applications generally contain the invention title, the results of experiments and a technical description of the patent. Therefore, it is possible to analyze the process of recording information about the inventors or organizations active in the field of technology.

During the analysis process, assuming that past trends will continue, a very large collection of historical data

\section{Figure 6. The relationship between codes}

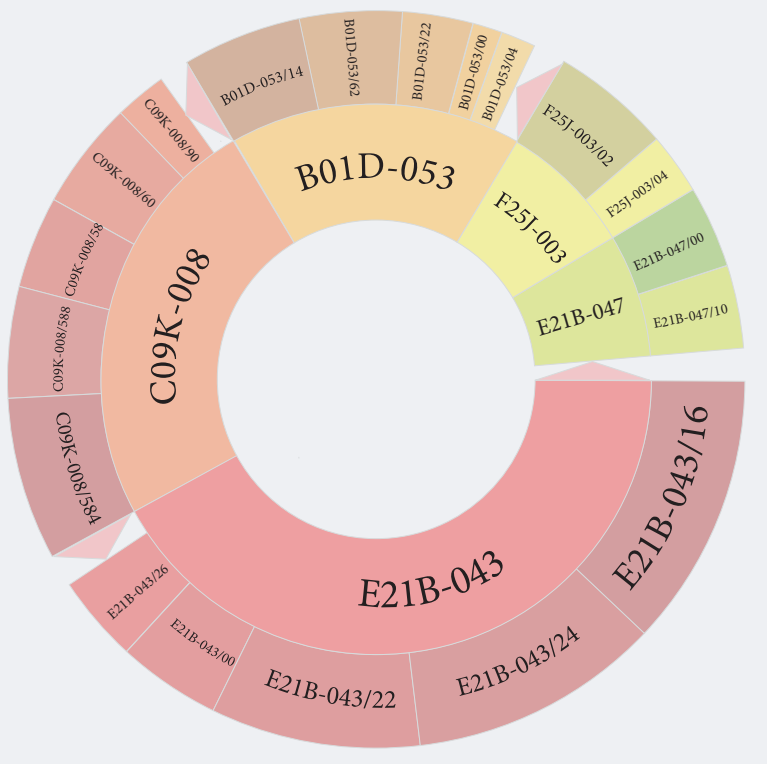

Source: compiled by the authors using Questel data for 2014.

\footnotetext{
${ }^{4}$ Available at: http://www.questel.com, accessed 17.02.2016.
} 


\section{Figure 7. The research framework}

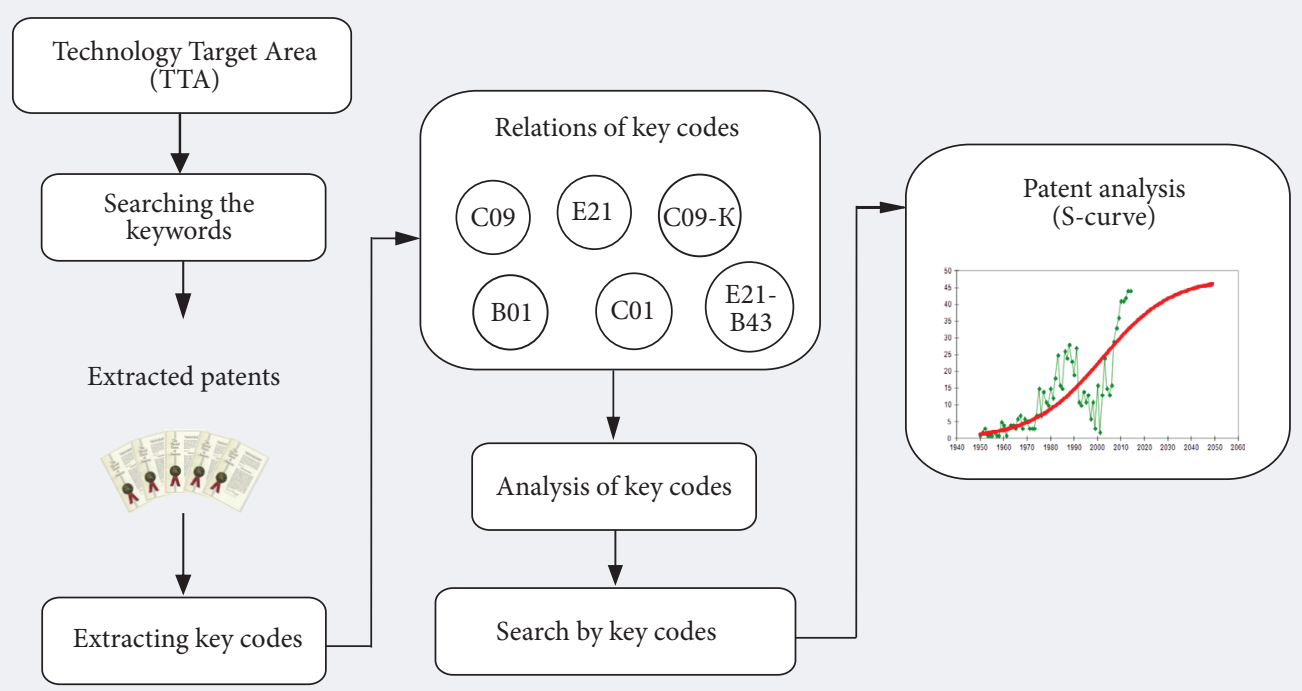

Source: compiled by the authors.

was collected and based on that, a picture of future developments is elaborated upon. These methods are appropriate for predicting the short term trends and providing an initial estimate of long-term developments. Moreover, these methods are used due to their lack of subjectivity.

Based on the data obtained on patents in the field of $\mathrm{CO}_{2}$ injection technology, we classified the patent applications into three periods. The first period corresponded with the emerging era when the technology was introduced; this stage was between 1937 and 1957 where a weak growth was observed (not a patent filing was observed in the period of 1938-1948). The next period was from 1958 to 1988, when most probably due to oil crises and high oil prices, the number of patents filed increased and hence this period was considered the growth era. During the last period, despite patent fluctuations observed in patenting activities, the growth ratio was constant.

In Figure 8, two peaks are observed, and the distance between them shows increasing attention from researchers, inventors and companies in carbon dioxide injection technology during EOR.

In the first period, which started from 1937 due to a lack of enthusiasm in this technology the number of patents were negligible, the highest number of patents were filed in 1949. The second period began with 5 patents in 1961 and continued to rapidly grow until 1988. The largest number of patents filed in one year was 26 , which created a revolution in the technology. This rapid growth can be attributed to various events such as the embargo war which caused large fluctuations in oil prices. Figure 9 illustrates this fact.

\section{Figure 8. $\mathrm{CO}_{2}$ injection technology patent application trend}

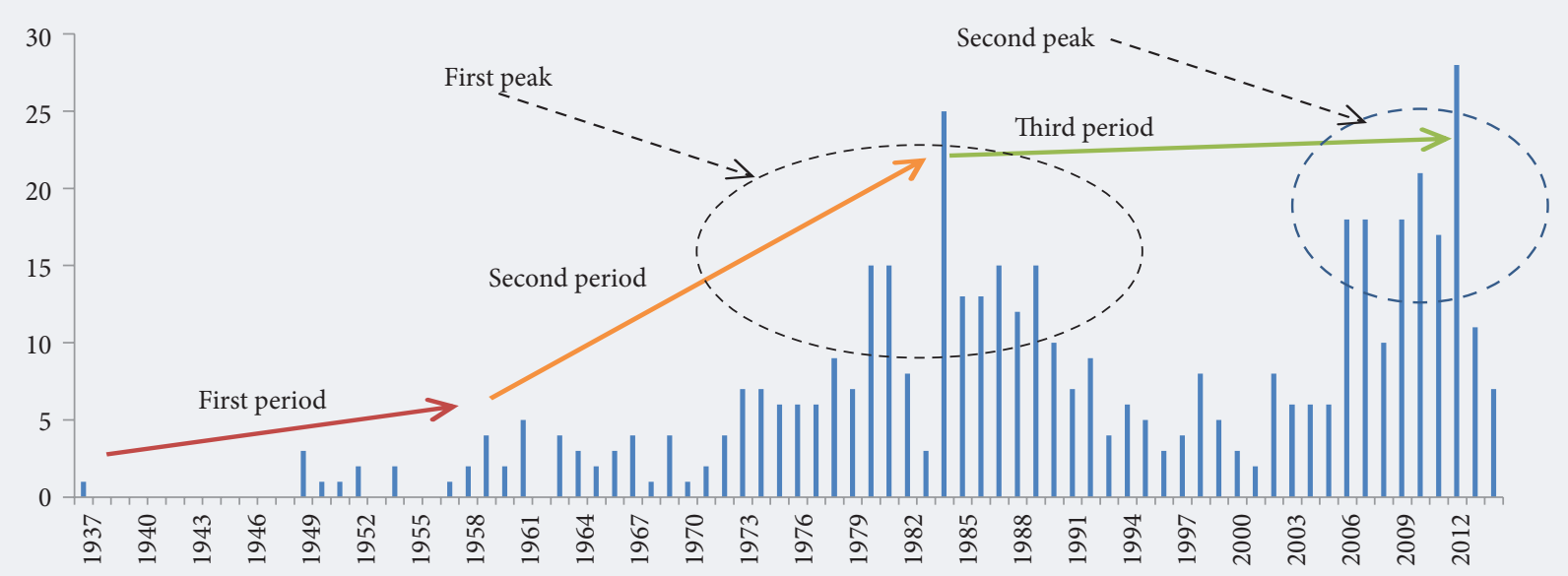

Source: compiled by the authors. 


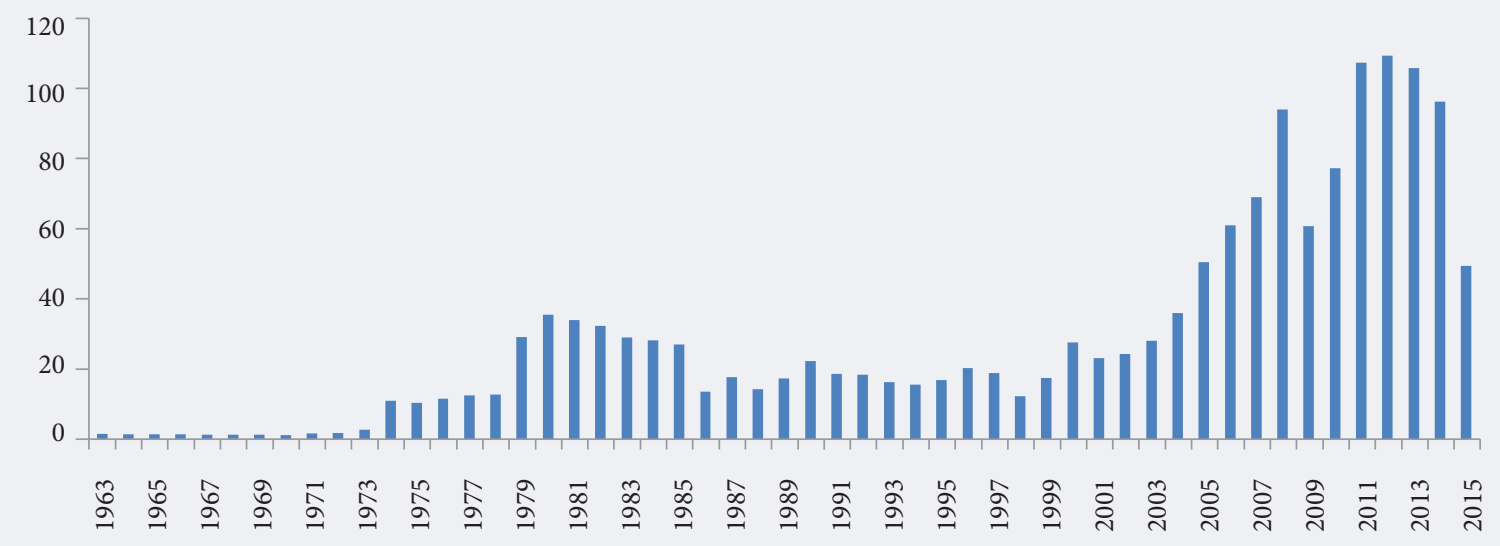

Source: compiled by the authors.

According to Figure 9, the fluctuations in oil prices has a significant effect on technology related to the oil industry, including $\mathrm{CO}_{2}$ injection technology. The patent application trend clearly follows the oil price, although different issues such as the introduction of renewable energy, environmental challenges and also new technology in this category have had an impact on $\mathrm{CO}_{2}$ injection technology.

Figure 10 shows the activities of companies over time. In 1957 this rather unknown ${ }^{5}$ technology came to the attention of companies.

The results of the S-curves modeling for the $\mathrm{CO}_{2}$ injection technology and the acquired data are shown and discussed below.

According to Figure11, there was slow growth in the number of $\mathrm{CO}_{2}$ injection patents (and hence technology) between 1937-1957. The inflection points of the S-curve are located between 1985 and 1995 based on the data at hand. Next, the growth slows down and reaches the final saturation point, which is forecast to happen between 2040 and 2050 .

\section{Conclusion}

A technology forecasting model based on the analysis of a frequent time series was used. We applied the S-Curve model to a $\mathrm{CO}_{2}$ injection technology forecasting analysis that was constructed using annual

\section{Figure 10. Dynamics of patent activities of oil and gas companies in relation to $\mathrm{CO}_{2}$ injection} technology (number of registered patent applications per year)

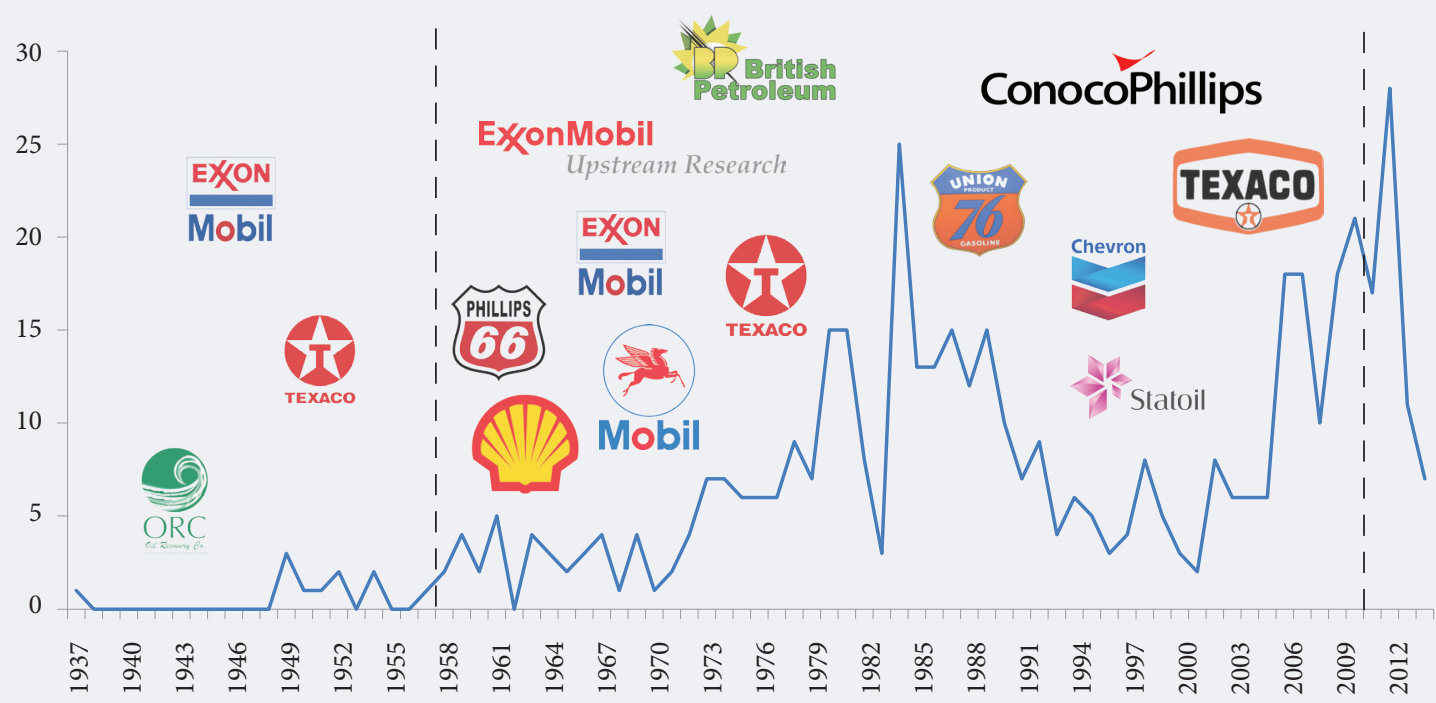

Source: compiled by the authors.

${ }^{5}$ An unknown technology can be described as a new technology whose attributes are not yet identified. 


\section{Figure 11. The S-curve cycle}

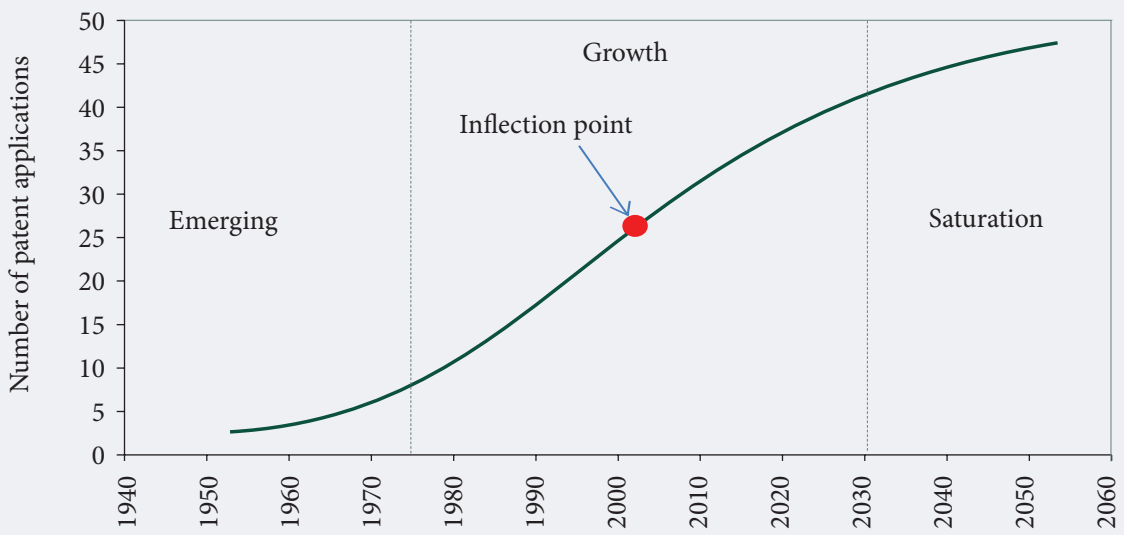

Source: compiled by the authors.

frequency in $\mathrm{CO}_{2}$ injection technology patents. According to the data obtained based on patenting activities in $\mathrm{CO}_{2}$ injection technology, we divided patent applications into three periods.

The first period, i.e. the emerging era, includes the introduction of the technology and was found to be around 1937-1957. During this period the patenting activities are characterized by slow growth. Next was the period between 1958-1988 when the growth rates are much higher, most likely due to thenoil crisis and high oil prices. This period is consider the growth era. In last period, despite the fluctuations in patenting activity, the overall growth rates were constant. Based on the trend and life cycle analyses (S-Curve), the $\mathrm{CO}_{2}$ injection technology can be considered to be in its maturity period and it was forecast to reach saturation between 2040 and 2050.

This research has described an approach and a method for identifying and analyzing the emerging to saturation stages of technologies, based on an analysis of published patent applications. The methods described in this report can be used by firms and their investors to monitor their technology, by placing their patents on S-curves. A firm or investor can evaluate the level of technology based on the S-curve's magnitude and duration. The results of this paper can provide a strong rationale for analysts who intend to use patents in technology forecasting. In this paper, the authors applied the described model to $\mathrm{CO}_{2}$ injection in EOR. The experimental data were created using frequency by year in $\mathrm{CO}_{2}$ injection in EOR technology patents.

As a further research, we are interested in improving our work using the latest data mining techniques. Moreover, we plan to use our approach for other emerging technologies in addition to ubiquitous technologies.

\section{References}

Amy J.C.T., Charles V.T. (2008) An R\&D knowledge management method for patent document summarization. Industrial Management \& Data Systems, vol. 108, no 2, pp. 245-257. DOI: 10.1108/02635570810847608.

Basberg B.L. (1987) Patents and the measurement of technological change: A survey of the literature. Research Policy, vol. 16, no 2, pp. 131-141.

Chen Y.-H., Chen C.-Y., Lee S.-C. (2011) Technology forecasting and patent strategy of hydrogen energy and fuel cell technologies. International Journal of Hydrogen Energy, vol. 36, no 12, pp. 6957-6969. DOI: http://dx.doi. org/10.1016/j.ijhydene.2011.03.063.

Daim T.U., Rueda G., Martin H., Gerdsri P. (2006) Forecasting emerging technologies: Use of bibliometrics and patent analysis. Technological Forecasting and Social Change, vol. 73, no 8, pp. 981-1012.

DOE (2011) Improving Domestic Energy Security and Lowering $\mathrm{CO}_{2}$ Emissions with "Next Generation" CO -Enhanced Oil Recovery (CO2-EOR) (DOE/NETL-2011/1504), Washington, D.C.: U.S. Department of Energy, National Energy Technology Laboratory.

Dou H. J.-M. (2004) Benchmarking R\&D and companies through patent analysis using free databases and special software: A tool to improve innovative thinking. World Patent Information, vol. 26, no 4, pp. 297-309.

Ernst H. (2003) Patent information for strategic technology management. World Patent Information, vol. 25, no 3, pp. 233-242.

Gao L., Porter A. L., Wang J., Fang S., Zhang X., Ma T., Wang W., Huang L. (2013) Technology life cycle analysis method based on patent documents. Technological Forecasting and Social Change, vol. 80, no 3, pp. 398-407.

Intepe G., Koc T. (2012) The Use of S-curves in Technology Forecasting and its Application on 3D TV Technology. International Journal of Mechanical, Aerospace, Industrial, Mechatronic and Manufacturing Engineering, vol. 6, no 11, pp. 2491-2495.

Little A.D. (1981) The Strategic Management of Technology, Cambridge, MA: Massachusetts Institute of Technology.

Malik Q.M., Islam M.R. (2000) CO Injection in the Weyburn Field of Canada: Optimization of Enhanced Oil Recovery and Greenhouse Gas Storage With Horizontal Wells. Paper presented at the SPE/DOE Improved Oil Recovery Symposium, 3-5 April, 2000, Tulsa, Oklahoma.

Mogee M.E. (1991) Using patent data for technology analysis and planning. Research-Technology Management, vol. 34 , no 4 , pp. 43-49. 